\title{
Glucose metabolism-related protein 1 (GMRP1) regulates pancreatic beta cell proliferation and apoptosis via activation of Akt signalling pathway in rats and mice
}

\author{
X. Wang $\cdot$ Y. Liu $\cdot$ Z. Yang $\cdot$ Z. Zhang $\cdot$ W. Zhou \\ Z. Ye $\cdot$ W. Zhang $\cdot$ S. Zhang $\cdot$ Z. Yang $\cdot$ X. Feng $\cdot$ \\ F. Chen $\cdot$ R. Hu
}

Received: 19 August 2010 /Accepted: 10 December 2010/Published online: 26 January 2011

(C) Springer-Verlag 2011

\begin{abstract}
Aims/hypothesis We attempted to elucidate the impacts on and possible mechanisms by which glucose metabolismrelated protein 1 (GMRP1) affects beta cell survival.

Methods Adenovirus-mediated GMRP1 overproduction and siRNA-mediated knockdown were performed in INS$1 \mathrm{E}$ cells and rat islets, after which cell proliferation or apoptosis were determined, and phosphorylation of Akt and BCL2-associated agonist of cell death (BAD) investigated. INS-1E cells and rat islets were cultured at 5.6 (low) or $25 \mathrm{mmol} / \mathrm{l}$ (high) glucose for 24 or $48 \mathrm{~h}$, and cell proliferation or apoptosis and GMRP1 levels were investigated. INS-1E cells were treated for $24 \mathrm{~h}$ with $0,10,50$ and $100 \mathrm{nmol} / \mathrm{l}$ insulin, and GMRP1 levels were determined. After INS-1E cells were transfected with siRNA for $72 \mathrm{~h}$, high glucose-induced cell proliferation and insulinstimulated Akt phosphorylation were investigated. Glucose-infused rat models were established and beta cell proliferation and mass were evaluated. Levels of GMRP1, and phosphorylation of Akt and BAD were determined in
\end{abstract}

X. Wang, Y. Liu, Z. Yang and Z. Zhang contributed equally to this study.

X. Wang $(\bowtie) \cdot Z$. Yang $\cdot$ Z. Zhang $\cdot$ W. Zhou $\cdot$ Z. Ye $\cdot$ W. Zhang $\cdot$

S. Zhang $\cdot$ Z. Yang $\cdot$ X. Feng $\cdot$ F. Chen $\cdot$ R. Hu $(\bowtie)$

Department of Endocrinology, Huashan Hospital,

Shanghai Medical College, Fudan University,

12 Wulumuqi Road (Middle),

Shanghai 200040, People's Republic of China

e-mail: wangxch@fudan.edu.cn

e-mail: renminghu@fudan.edu.cn

Y. Liu

Department of Geriatric Endocrinology, General Hospital of PLA,

Beijing, People's Republic of China glucose-infused islets. The GMRP1-mediated Akt pathway was also investigated in $d b / d b$ mice.

Results Overproduction of GMRP1 promoted beta cell proliferation via increased phosphorylation of Akt. Knockdown of Gmrpl (also known as Btbd10) reduced phosphorylation of Akt with enhanced beta cell apoptosis. High glucose increased GMRP1 levels and cell proliferation in INS-1E cells and islet cells. Knockdown of Gmrp I decreased high glucose-induced cell proliferation and insulin-stimulated Akt phosphorylation. Increased GMRP1 levels were involved in the enhancement of beta cell proliferation and mass in glucose-infused islets. Decreased GMRP1 levels may participate in beta cell apoptosis of $d b / d b$ mice.

Conclusions/interpretation GMRP1 regulates pancreatic beta cell proliferation and apoptosis via activation of Akt signalling pathway.

Keywords Akt $\cdot \mathrm{BAD} \cdot$ Beta cell survival $\cdot d b / d b$ mice . Glucose-infused rat $\cdot$ GMRP1

$\begin{array}{ll}\begin{array}{l}\text { Abbreviations } \\ \text { Ad-GFP }\end{array} & \begin{array}{l}\text { Recombinant adenovirus expressing } \\ \text { enhanced green fluorescent protein } \\ \text { Recombinant adenovirus containing } \\ \text { full-length cDNA of rat Gmrp1 }\end{array} \\ \text { Bd-GMRP1 } & \begin{array}{l}\text { BCL2-associated agonist of cell death } \\ \text { Green fluorescent protein }\end{array} \\ \text { GFP } & \text { Glucose metabolism-related protein 1 } \\ \text { GMRP1 } & \text { 3-Phosphoinositide-dependent protein } \\ \text { PDK-1 } & \text { kinase-1 } \\ \text { siRNA } & \text { Small interfering RNA }\end{array}$




\section{Introduction}

Diabetes mellitus, whether type 1 or type 2 , results from an inadequate mass of functional pancreatic beta cells [1]. The control of beta cell mass is a dynamic process and depends on a subtle balance between cell proliferation and growth, and cell death [2, 3]. Recent data suggest that adult pancreatic beta cells retain a significant proliferative capacity in vivo and that replication is a major component involved in maintenance of beta cell mass in adult animals $[4,5]$. Beta cell replication can be induced by many strategies and intrinsic factors [5-16]. The molecular mechanisms involved in regulation of beta cell proliferation are not fully understood. Several lines of evidence suggest that Akt and its mediated signalling pathway play critical roles in regulation of beta cell mass and function [12, 1720]. In most cases Akt activation is dependent on phosphoinositide-3-kinase. Once activated, Akt in turn phosphorylates a number of downstream targets that in general promote cell growth and survival [21]. BCL2associated agonist of cell death (BAD) is a well-established target of Akt $[22,23]$. It has been shown that Akt-mediated phosphorylation of BAD played an important role in the regulation of beta cell proliferation or apoptosis $[19,24]$.

In previous studies of our group, cDNA libraries of human hypothalamus, pituitary, adrenal and insulinoma tissues were established and several novel full-length cDNAs cloned $[25,26]$. A novel full-length cDNA cloned from human hypothalamus tissue was selected for further study and found to be related with glucose metabolism (X. Wang and R. Hu, unpublished data). We named this novel gene glucose metabolism-related protein 1 (GMRP1). The sequence data of human GMRP1 gene have been submitted to GenBank database under accession number AF329102. GMRP1 is the alias of BTBD10, the official name given by HUGO Gene Nomenclature Committee. BTBD10 was first described by Chen et al. [27] and found to be downregulated in gliomas. In another study by Nawa et al. [28], BTB (POZ) domain containing 10, the protein encoded by BTBD10, was found to interact with Akt by yeast two-hybrid and appeared to behave as a suppressor of neuronal cell death and an enhancer of cell growth via its positive regulation of Akt phosphorylation.

The current study attempted to investigate whether glucose metabolism-related protein 1 (GMRP1) regulates Akt signalling pathway in beta cells and whether GMRP1 exerts impacts on beta cell proliferation or apoptosis.

\section{Methods}

Animals We used Sprague-Dawley male rats (age 2 months), male $d b / d b$ mice (age 5 months) and age-matched
C57BLKS/J mice, all obtained from the Experimental Animal Center, Shanghai Medical College of Fudan University. All experimental procedures were approved by the Shanghai Animal Care and Use Committee on Animals and followed the policies of the International Association for the Study of Pain on the use of laboratory animals. All efforts were made to minimise animal suffering and reduce the numbers of the animals used.

Northern blot analysis Target gene fragments of human GMRP1 were cloned into pDrive vectors (Qiagen, Chatsworth, CA, USA). Digoxigenin-labelled probes were generated by transcription with $S P 6 / T 7$ RNA polymerase using a digoxigenin RNA labelling kit (Roche Diagnostics, Indianapolis, IN, USA). Human tissues including human islets were obtained from Shanghai Body Donation Center. Use of those tissues was approved by the Medical Ethics Committee at Huashan Hospital, Fudan University. Northern blotting was performed using a kit (non-isotopic digoxigenin Northern Starter; Roche Diagnostics) as described previously [29].

Preparation of polyclonal antibody against human GMRP1 The complete cDNA sequence of human GMRP1 gene was subcloned into pET32 vector (Novagen, Madison, WI, USA). The recombinant pET32-GMRP1 vector was transformed into E. coli strain BL21. Recombinant GMRP1 protein was produced and purified, and polyclonal antibody against human GMRP1 generated by immunising rabbits as described previously [29].

Immunostaining analysis Pancreatic tissues from (1) Sprague-Dawley rats infused with saline and high glucose, (2) $d b / d b$ mice and (3) C57BLKS/J mice were fixed overnight in formalin at room temperature, along with human insulinoma tissues, and then dehydrated, embedded in paraffin and sectioned $(5 \mu \mathrm{m})$. For GMRP1 and insulin double immunohistochemistry, rabbit anti-GMRP1 polyclonal antibody and goat anti-insulin monoclonal antibody (Santa Cruz Biotechnology, Santa Cruz, CA, USA) were used to incubate the same section sequentially and the sections were incubated with anti-rabbit $\mathrm{IgG}$ antibody conjugated with alkaline phosphatase (Pierce, Rockford, IL, USA) to stain for GMRP1, followed by incubation with horseradish peroxidase-conjugated anti-goat IgG antibody (Pierce) to stain for insulin. The sections were then observed and imaged using a microscope (Leica Microsystems, Wetzlar, Germany). For Ki67 and insulin immunofluorescence, guinea pig anti-insulin polyclonal antibody (Abcam, Cambridge, MA, USA) and rabbit monoclonal antibody against Ki67 (Abcam) were used as primary antibodies, followed by staining for insulin with FITCconjugated anti-guinea pig IgG antibody (Jackson Immu- 
noResearch Laboratories, West Grove, PA, USA) and for Ki67 with Rhodamine-conjugated anti-rabbit $\operatorname{IgG}$ antibody (Jackson ImmunoResearch). Images were taken under a fluorescence microscope equipped with a charge-coupled device camera (Leica Microsystems).

Western blot analysis Total proteins were extracted from isolated islet cells and INS-1E cells using RIPA buffer (Pierce). Western blotting was performed as described previously [29].
Cell culture INS-1E cells kindly supplied by P. Maechler (Department of Cell Physiology and Metabolism, Faculty of Medicine, University of Geneva, Geneva, Switzerland) [30], were cultured according to the protocol described [30]. For experiments on regulation of GMRP1 by glucose or insulin, INS-1E cells were cultured to $60 \%$ confluence and treated with 5.6 or $25 \mathrm{mmol} / \mathrm{l}$ glucose for 24 or $48 \mathrm{~h}$, after which $0,10,50$ and $100 \mathrm{nmol} / 1$ insulin was administered for $24 \mathrm{~h}$. GMRP1 protein levels were investigated by western blotting. Apoptosis of INS-1E cells
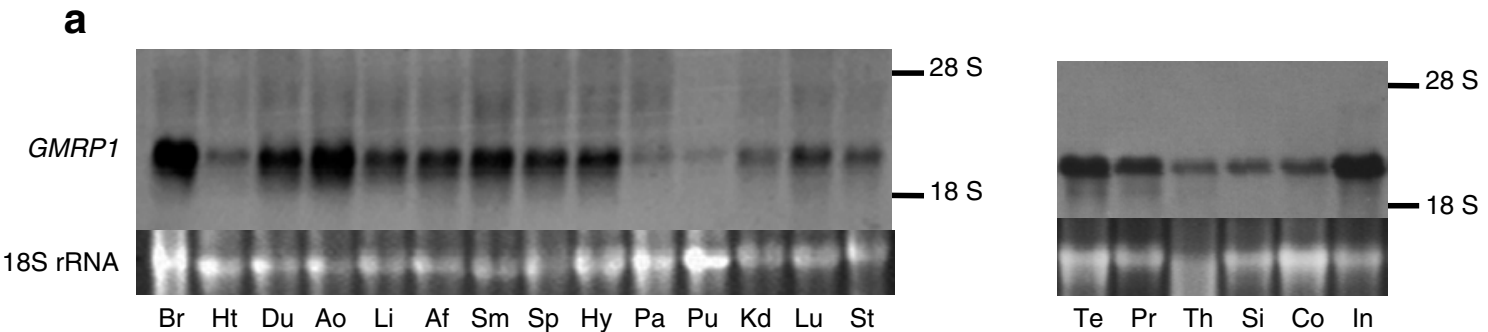

b

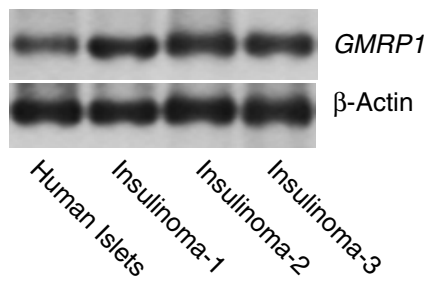

C

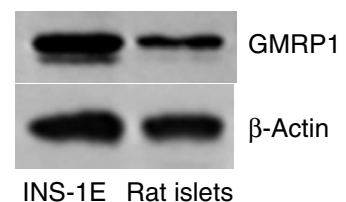

d

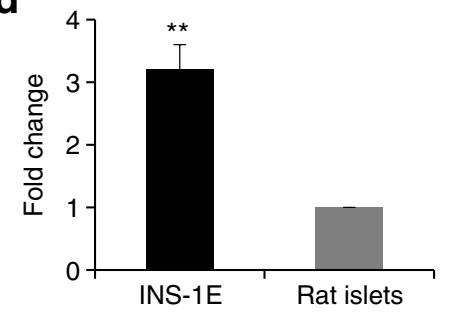

e

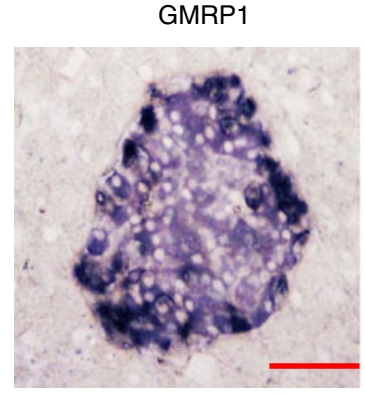

f

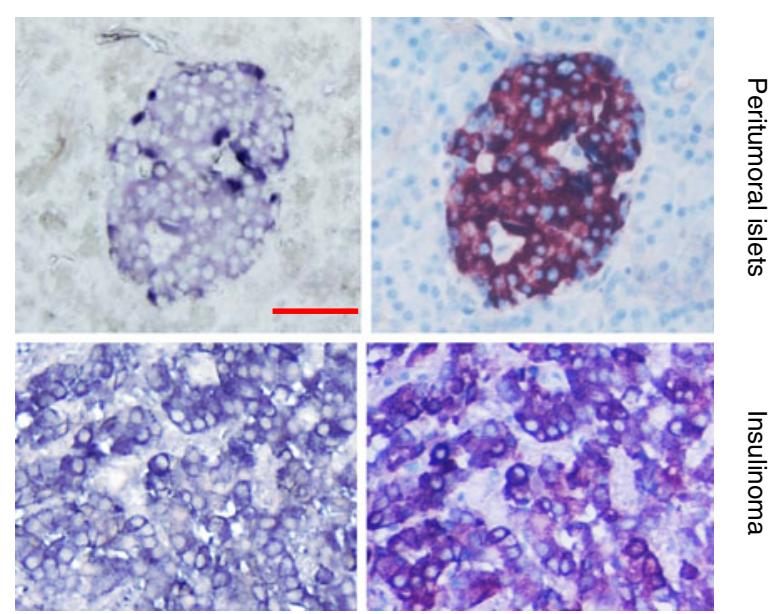

Fig. 1 Expression patterns of GMRPI and the protein it encodes. a Gene expression profile of human GMRP1. mRNA levels of GMRPI were detected in human tissues by northern blotting. Total RNA $(10 \mu \mathrm{g})$ isolated from human tissues as indicated was hybridised with a digoxigenin-labelled GMRPI RNA probe. 18S rRNA was used as control to confirm comparable RNA loading. The locations of $18 \mathrm{~S}$ and $28 \mathrm{~S}$ rRNA are indicated on the right. Af, abdominal fat; Ao, aorta; Br, brain; Co, colon; Du, duodenum; Ht, heart; Hy, hypothalamus; In, insulinoma; Kd, kidney; Li, liver; Lu, lung; Pa, pancreas; Pr, prostate; $\mathrm{Pu}$, pituitary; $\mathrm{Si}$, small intestine; Sm, skeletal muscle; Sp, spleen; St, stomach; Te, testis; Th, thymus. b Differential expression of GMRPI gene in human islets and insulinomas by northern blotting. $\mathbf{c}$ Levels of GMRP1 protein in rat islets and INS-1E cells by western blotting. d Statistical analysis of western blot (c). Level of GMRP1 in rat islets was set to $1 ;{ }^{* *} p<0.01$. e Cellular distribution of GMRP1 protein in mouse islets. The same pancreatic section from a C57BLKS/J mouse was immunostained for GMRP1 and insulin sequentially. f Immunohistochemistry analysis of GMRP1 in human insulinoma tissue and peritumoral islets. The same sections of insulinoma tissue and peritumoral islets were immunostained for GMRP1 and insulin sequentially. Scale bar, $100 \mu \mathrm{m}$ 
was evaluated by determination of histone-complexed DNA fragments using a kit (Cell Death Detection ELISA; Roche Molecular Biochemicals, Mannheim, Germany). The relative frequency of apoptosis was photometrically determined by measuring the peroxidase activity of the immunocomplexes at $405 \mathrm{~nm}$. Cell proliferation was assessed by $\left[{ }^{3} \mathrm{H}\right]$ thymidine incorporation according to the protocol described by El Ouaamari [31].

Islet isolation and treatment Islets of Langerhans were isolated from adult Sprague-Dawley rats, saline/high glucose-infused rats, C57BLKS/J mice and $d b / d b$ mice by in situ pancreas collagenase infusion and separated by density gradient centrifugation at $800 \mathrm{~g}$ according to the modified protocol described by Kinasiewicz [32]. Isolated islets were transferred to 24 -well plates and cultured in RPMI containing different glucose concentrations (5.6 and $25 \mathrm{mmol} / \mathrm{l})$ for different periods ( 24 and $48 \mathrm{~h}$ ) respectively. GMRP1 protein levels were investigated by western blotting and apoptosis of islet cells was evaluated by DNA fragmentation. Cell proliferation was assessed by $\left[{ }^{3} \mathrm{H}\right]$ thymidine incorporation. a

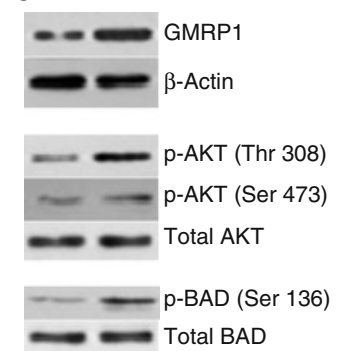

Adv-GFP Adv-GMRP1

\section{e}

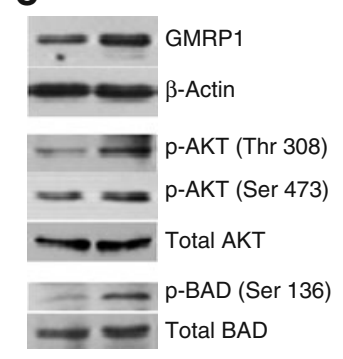

Adv-GFP Adv-GMRP1 b

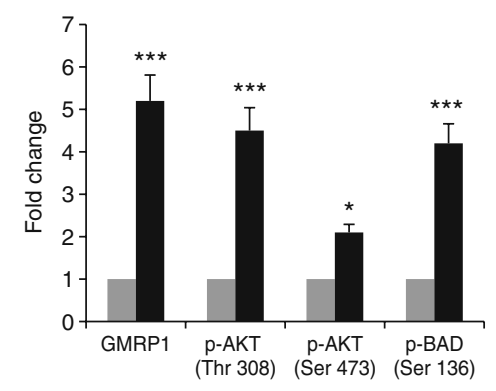

f

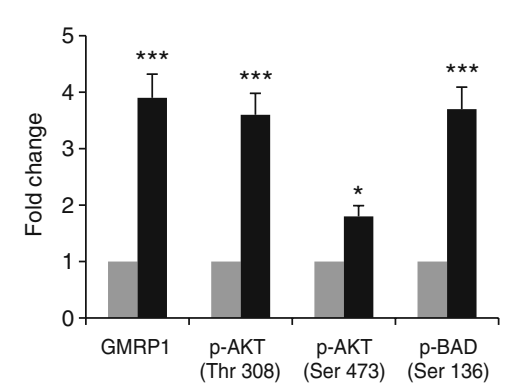

Adenovirus generation and infection Recombinant adenovirus containing full-length cDNA of rat Gmrpl (AdGMRP1) was generated using the AdMax cloning system (Microbix Biosystems, Toronto, ON, Canada) according to the protocol provided by the manufacturer. Recombinant adenovirus expressing enhanced green fluorescent protein (GFP) (Ad-GFP) was used as a control adenovirus. INS-1E cells or rat islet cells were cultured in six-well plates to $60 \%$ confluence and then infected with Ad-GMRP1 or Ad-GFP for $90 \mathrm{~min}$. Viruses were removed and fresh medium was added for an additional $72 \mathrm{~h}$ of incubation.

Small interfering RNA-mediated knockdown of Gmrp1 For Gmrp1 small interfering RNA (siRNA) experiments, 20- to 25-nucleotide stealth-prevalidated siRNA duplexes designed for rat Gmrpl (Invitrogen, Carlsbad, CA, USA) were used. INS-1E cells were seeded in six-well plates at a density of $\sim 5 \times 10^{5}$ cells per well in culture medium without antibiotics and transfected with Lipofectamine 2000 transfection reagent (Invitrogen) according to the manufacturer's instructions. Cells were transfected for $6 \mathrm{~h}$ with the Gmrp 1 siRNA at a final concentration of $50 \mathrm{nmol} / \mathrm{l}$ or with control
C

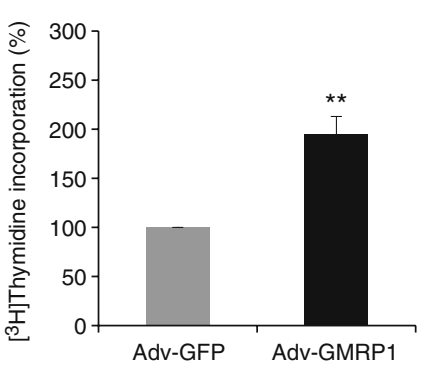

g

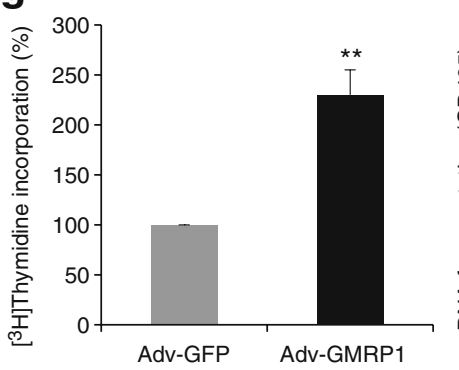

d

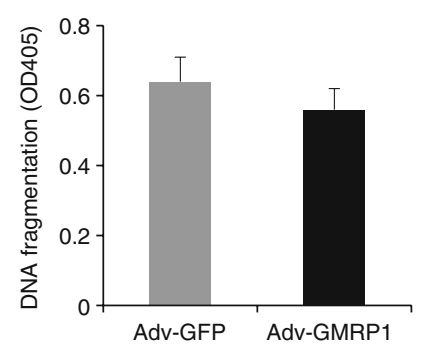

h

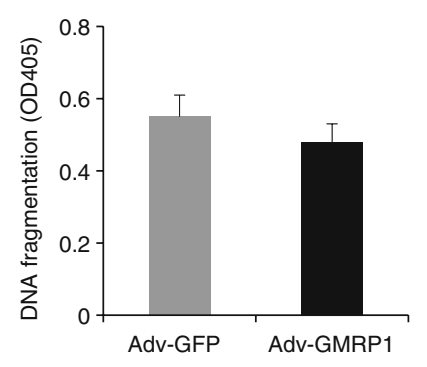

Fig. 2 Adenovirus-mediated overproduction of GMRP1 increased beta cell proliferation via Akt-BAD pathway. INS-1E cells (a-d) or rat islets $(\mathbf{e}-\mathbf{h})$ were transfected with Ad-GMRP1 or Ad-GFP for $72 \mathrm{~h}$, after which western blotting was used to detect levels of GMRP1, $\beta$-actin, total AKT, phosphorylated Akt (p-Akt) at Thr 308 or at Ser 473 , total BAD and phosphorylated BAD (p-BAD) at Ser 136 in INS$1 \mathrm{E}$ cells (a) or rat islets (e). b, f Results of statistical analysis of blots (a, e). Phosphorylation of Akt at Thr 308 or at Ser 473 was measured using p-Akt at Thr 308 or at Ser 473 divided by total Akt. Phosphorylation of BAD was evaluated similarly. The relative levels of GMRP1, p-AKT (Thr 308), p-AKT (Ser 473) and p-BAD (Ser 136) in Ad-GMRP1-transfected (black bars) INS-1E cells or rat islets are shown, vs corresponding levels in Ad-GFP-transfected (grey bars) cells or islets, which were set to $1 ;{ }^{*} p<0.05$ and ${ }^{* * *} p<0.001$. c, d INS-1E cells or $(\mathbf{g}, \mathbf{h})$ rat islets were infected with Ad-GMRP1 or AdGFP for $90 \mathrm{~min}$. Viruses were removed and fresh medium was added for an additional $72 \mathrm{~h}$ of incubation. Cell proliferation of INS-1E cells (c) or rat islets (g) was assessed by measuring $\left[{ }^{3} \mathrm{H}\right]$ thymidine incorporation; $* * p<0.01$. Cell apoptosis of INS-1E cells (d) or rat islets (h) was determined by DNA fragmentation assay. OD, optical density 
siRNA (non-targeting siRNA) at the same concentration before switching to fresh culture medium including antibiotics. At $72 \mathrm{~h}$ after transfection, cells were lysed to extract total protein or to detect apoptotic cells by DNA fragmentation or to investigate cell proliferation by $\left[{ }^{3} \mathrm{H}\right]$ thymidine incorporation. After transfection for $72 \mathrm{~h}$ with Gmrpl siRNA or control siRNA, INS-1E cells were treated with 5.6 or $25 \mathrm{mmol} / \mathrm{l}$ glucose for an additional $24 \mathrm{~h}$. Cell proliferation was then assessed by $\left[{ }^{3} \mathrm{H}\right]$ thymidine incorporation or cells were stimulated for $10 \mathrm{~min}$ with $100 \mathrm{nmol} / \mathrm{l}$ insulin, followed by western blot to determine phosphorylation of Akt at Thr 308 .

Infusions Male Sprague-Dawley rats $(\sim 250 \mathrm{~g})$ were randomly divided into six groups as follows: (1) rats infused with saline for $24 \mathrm{~h}(0.45 \%$ [wt $/ \mathrm{vol}$.] $\mathrm{NaCl}$ infusion); (2) rats infused with saline for $48 \mathrm{~h}$; (3) rats infused with saline for $72 \mathrm{~h}$ : (4) rats infused with glucose for $24 \mathrm{~h}(50 \%$ [wt/vol.] dextrose infusion, at $2 \mathrm{ml} / \mathrm{h}$ ); (5), rats infused with glucose for $48 \mathrm{~h}$; and (6) rats infused with glucose for $72 \mathrm{~h}$. The infusion technique was similar to that described by Bonner-Weir et al. [33]. At the end of the infusion period, animals were removed from the restraint system, returned to their cages and eventually killed for morphological assessment of beta cell mass and proliferation, or for islet isolation.

Beta cell replication Beta cell replication was evaluated using measurement of Ki67-postive beta cells in islets of rats infused with saline or glucose. Pancreatic sections were double-stained with anti-Ki67 antibody and anti-insulin antibody as described above. On these sections, beta cells showed green cytosol and Ki67-postive cells appeared with red nuclei. Ki67-postive beta cells were counted by systematically sampling all of the beta cells identified by insulin staining in each section using a light microscope under high magnification $(\times 1,000)$. The proportion of Ki67-postive beta cell nuclei to total beta cell nuclei was calculated.

Measurement of beta cell mass To measure beta cell mass, pancreatic sections $(5 \mu \mathrm{m})$ were incubated overnight at $4^{\circ} \mathrm{C}$ with guinea pig anti-insulin polyclonal antibody (1:200 dilution; Abcam) and then incubated with biotinylated antiguinea pig $\operatorname{IgG}$ antibody and with avidin-biotin-peroxidase complex (Vector, Burlingame, CA, USA). Point-counting morphometry of insulin immunostained pancreatic sections as applied by Montaña [34] was used to calculate the relative beta cell volume as a measure of beta cell mass.

TUNEL assay Pancreas sections of $d b / d b$ or control mice were double immunostained for insulin and for fragmented DNA by TUNEL assay. TUNEL staining was carried out using a DNA fragmentation detection kit (FragEL; Merck, Darmstadt, Germany) according to the manufacturer's instructions. Cells were counted (1,000 cells per sample) and the number of TUNEL-positive cells quantified and expressed as a percentage of the total.

Statistical analysis Data are presented as means \pm SEM. Statistical significance was determined by ANOVA, with $p<0.05$ considered significant.

\section{Results}

Expression pattern of GMRP1 gene and its protein $\mathrm{We}$ established gene expression profile of human GMRP1. The results of northern blotting demonstrated that GMRPI mRNA was ubiquitously expressed in human tissues, with high expression especially in brain, aorta, testis and insulinoma tissues (Fig. 1a). We also compared GMRP1 mRNA levels between human islets and insulinomas, and found much greater expression of GMRP1 in insulinoma tissues than in human islets (Fig. 1b). The results of a
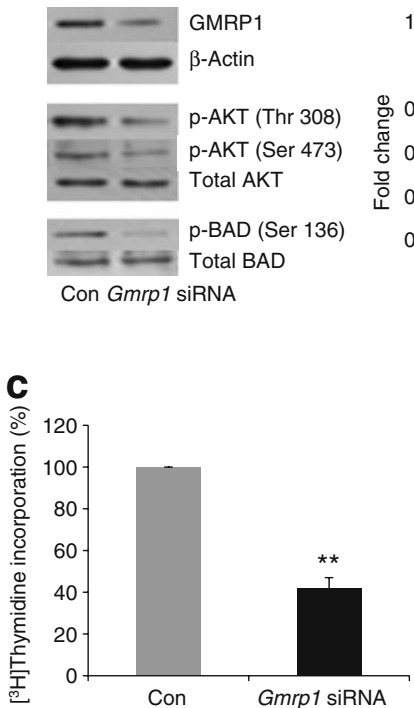

b

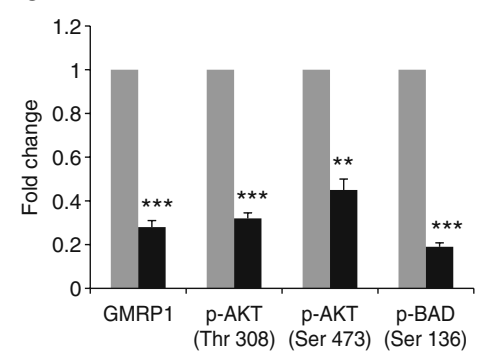

d

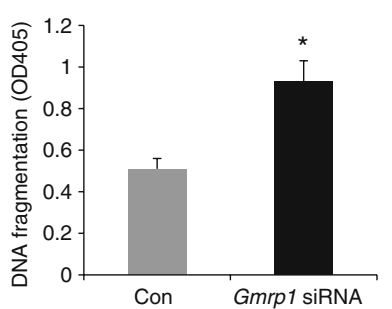

Fig. 3 siRNA-mediated knockdown of GMRP1 inhibited proliferation and induced apoptosis of INS-1E cells. INS-1E cells were transfected with Gmrpl siRNA or control siRNA (Con) for $72 \mathrm{~h}$, after which levels of GMRP1, $\beta$-actin, total AKT, phosphorylated Akt (p-Akt) at Thr 308 or at Ser 473, as well as total BAD and phosphorylated BAD (p-BAD) at Ser 136 were determined by western blotting (a). b Statistical analysis of blot (a). Phosphorylation of Akt at Thr 308 or at Ser 473 was measured using p-Akt at Thr 308 or at Ser 473 divided by total Akt. Phosphorylation of BAD was evaluated similarly. The relative levels of GMRP1, p-AKT (Thr 308), p-AKT (Ser 473) and p-BAD (Ser 136) in Gmrpl siRNA-transfected (black bars) INS-1E cells are shown, with control siRNA-transfected (grey bars) cells set to $1 ;{ }^{* *} p<0.01$ and $* * * p<0.001$. After INS-1E cells were transfected with Gmrpl siRNA or control siRNA for $72 \mathrm{~h}$, cell proliferation (c) was assessed by measuring $\left[{ }^{3} \mathrm{H}\right]$ thymidine incorporation; ${ }^{* *} p<0.01$. d Cell apoptosis was determined by DNA fragmentation assay; ${ }^{*} p<0.05$. OD, optical density 
immunohistochemistry also indicated higher levels of GMRP1 protein in insulinoma tissue than in peritumoral normal islets (Fig. 1f). Western blot analysis demonstrated that levels of GMRP1 in INS-1E cells increased 3.2-fold in comparison with those in rat islets (Fig. 1c, d). Immunohistochemistry analysis also showed that GMRP1 was predominantly produced in islets of mouse pancreas tissue and was hardly detected in exocrine tissue. In detail, according to the architecture of islets and insulin staining, GMRP1 appeared to be more abundant in non-beta cells than in beta cells (Fig. 1e).

a

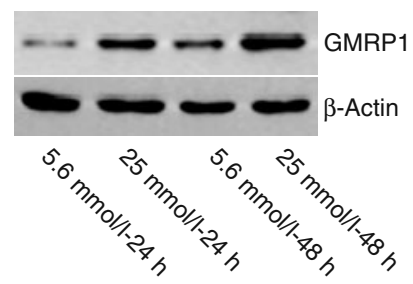

e

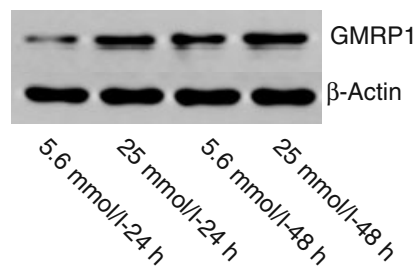

b

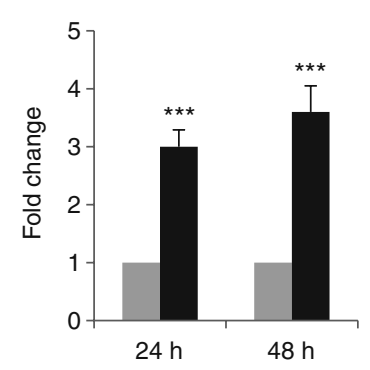

f

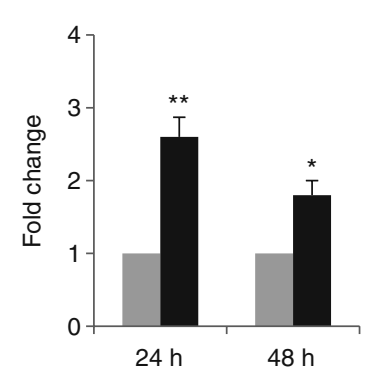

Overproduction of GMRP1 promoted beta cell proliferation via $A k t-B A D$ pathway INS-1E cells or rat islets were transfected with Ad-GMRP1 or Ad-GFP for $72 \mathrm{~h}$, and phosphorylation of Akt or BAD, and cell proliferation or apoptosis were determined. When compared with Ad-GFP, Ad-GMRP1 transfection significantly increased phosphorylation of Akt at Thr 308, namely 4.5-fold for INS-1E cells $(p<0.001$; Fig. 2a, b) and 3.6-fold for rat islets $(p<0.001$; Fig. 2e, f). It also significantly increased phosphorylation of Akt at Ser 473, namely 2.1-fold for INS-1E cells $(p<0.05$; Fig. $2 \mathrm{a}, \mathrm{b})$ and 1.8 -fold for rat islets $(p<0.05$; Fig. $2 \mathrm{e}, \mathrm{f})$, as

C

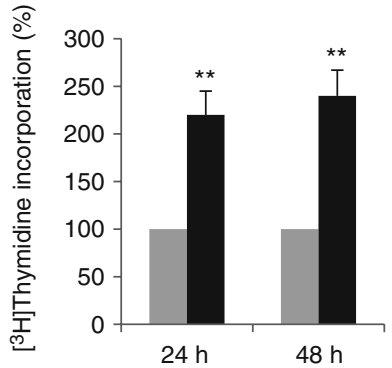

g

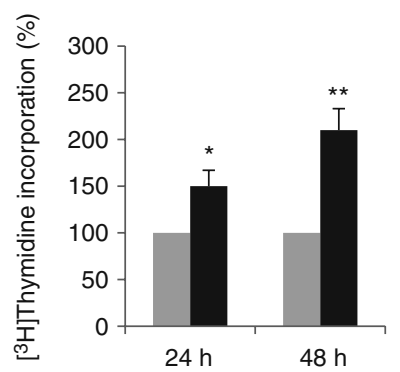

d

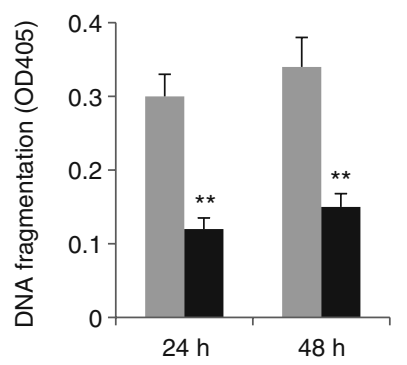

h

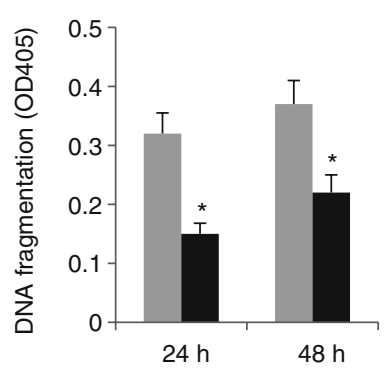

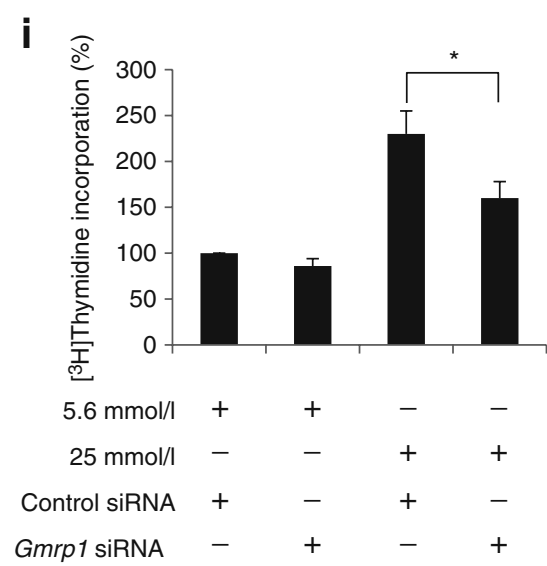

Fig. 4 Impacts of glucose on GMRP1 levels and cell survival. a-d INS$1 \mathrm{E}$ cells or $(\mathbf{e}-\mathbf{h})$ rat islets were treated with 5.6 or $25 \mathrm{mmol} / 1$ glucose for 24 and $48 \mathrm{~h}$ respectively. Production of GMRP1 protein in INS-1E cells (a) or rat islets (e) was investigated using western blotting and quantified by statistical analysis with GMRP1 protein levels at $5.6 \mathrm{mmol} / 1$ glucose (grey bars) set to 1 for (b) INS-1E cells $(* * * p<0.001)$ and (f) for rat islets $(* p<0.05, * * p<0.01$ and $* * * p<$ 0.001). Black bars, $25 \mathrm{mmol} / 1$. c $\left[{ }^{3} \mathrm{H}\right]$ Thymidine incorporation was used to assess cell proliferation in INS-1E cells $(* * p<0.01)$ and $(\mathbf{g})$ rat islets $\left(* p<0.05\right.$ and $\left.{ }^{* *} p<0.01\right)$. d DNA fragmentation assay was performed to evaluate apoptosis in INS-1E cells $(* * p<0.01)$ and (h) rat islets $\left({ }^{*} p<0.05\right)$. $\mathbf{i}$ To investigate whether GMRP1 is involved in glucose-regulated cell survival, INS-1E cells were transfected with Gmrpl siRNA or control siRNA for $72 \mathrm{~h}$ and then treated with 5.6 or $25 \mathrm{mmol} / 1$ glucose for an additional $24 \mathrm{~h}$, after which cell proliferation was determined; ${ }^{*} p<0.05$ 
well as phosphorylation of BAD at Ser 136 (4.2-fold for INS-1E cells, $p<0.001$; 3.7-fold for rat islets, $p<0.001$; Fig. 2a, b, e, f). $\left[{ }^{3} \mathrm{H}\right]$ Thymidine incorporation analysis demonstrated that overproduction of GMRP1 led to a twofold increase of proliferation in INS-1E cells $(p<0.01$; Fig. 2c) and a 2.3-fold increase in rat islets $(p<0.01$; Fig. 2g) compared with GFP control. However, DNA fragmentation showed that there were no significant differences in cell apoptosis between Ad-GMRP1 and Ad-GFP transfected INS-1E cells (Fig. 2d) or rat islets (Fig. 2h).

siRNA-mediated knockdown of Gmrp1 inhibited proliferation and induced apoptosis of INS-1E cells After INS-1E cells were transfected with Gmrpl siRNA or control siRNA for $72 \mathrm{~h}$, phosphorylation of Akt or BAD, and cell proliferation or apoptosis were determined. Western blot analysis indicated that transfection with Gmrpl siRNA resulted in $\sim 75 \%(p<0.001)$ reduction of GMRP1 protein, and in $\sim 70 \%(p<0.001), \sim 55 \%(p<0.01)$ and $\sim 80 \% \quad(p<0.001)$ decreases in phosphorylation of Akt at Thr 308 and Ser 473, and of BAD at Ser 136 respectively compared with control siRNA (Fig. 3a, b). Knockdown of Gmrpl reduced cell proliferation by $\sim 60 \%$ ( $p<0.01$; Fig. $3 c$ ) and increased cell apoptosis by $80 \%$ in comparison with controls $(p<0.05$; Fig. $3 \mathrm{~d})$.

Impact of glucose on GMRP1 levels and cell survival To investigate whether GMRP1 production was regulated by glucose, INS-1E cells or rat islets were cultured at 5.6 or $25 \mathrm{mmol} / \mathrm{l}$ glucose for 24 and $48 \mathrm{~h}$ respectively. GMRP1 protein in INS-1E cells was augmented 3.1-fold $(p<0.001)$ and 3.6-fold $(p<0.001)$ by exposure to $25 \mathrm{mmol} / \mathrm{l}$ glucose for 24 and $48 \mathrm{~h}$ respectively, when compared with $5.6 \mathrm{mmol} / 1$ glucose (Fig. 4a, b). In rat islets, high glucose also significantly increased GMRP1 levels during $24 \mathrm{~h}$ (2.6-fold, vs low glucose, $p<0.01)$ and $48 \mathrm{~h}(1.8$-fold, vs low glucose, $p<0.05$ ) of culture (Fig. $4 \mathrm{e}, \mathrm{f}$ ).

Proliferation of INS-1E cells was increased 2.2-fold $(p<0.01)$ and 2.4 -fold $(p<0.01)$ by exposure to $25 \mathrm{mmol} / 1$ glucose for 24 and $48 \mathrm{~h}$ respectively when compared with $5.6 \mathrm{mmol} / \mathrm{l}$ glucose (Fig. 4c). Cell proliferation of rat islets was also significantly increased by high glucose for $24 \mathrm{~h}(1.5$-fold vs low glucose, $p<0.05)$ and $48 \mathrm{~h}(2.1$-fold vs low glucose, $p<0.01$; Fig. $4 \mathrm{~g}$ ). DNA fragmentation analysis demonstrated that high glucose reduced apoptotic INS-1E cells about $60 \%(p<0.01)$ and $55 \%(p<0.01)$ for 24 and $48 \mathrm{~h}$ of culture respectively, when compared with low glucose (Fig. 4d). For rat islet cells, high glucose culture for 24 and $48 \mathrm{~h}$ led to $53 \%(p<0.05)$ and $41 \% \quad(p<0.05)$ reductions of the apoptotic cells respectively (Fig. 4h).

To confirm whether GMRP1 is involved in beta cell survival regulated by glucose, INS-1E cells were transfected with Gmrpl siRNA or control siRNA for $72 \mathrm{~h}$ and then treated with 5.6 or $25 \mathrm{mmol} / \mathrm{l}$ glucose for an additional $24 \mathrm{~h}$, after which cell proliferation was determined. Knockdown of Gmrpl lowered high glucose-induced cell proliferation by $\sim 30 \%$ ( $p<0.05$; Fig. $4 \mathrm{i})$.

Involvement of GMRP1 in insulin signalling pathway To determine the mechanism by which glucose regulates GMRP1 production, we investigated whether insulin administration without change of glucose concentration affected GMRP1 levels. INS-1E cells were cultured at 0 , 10,50 and $100 \mathrm{nmol} / 1$ insulin for $24 \mathrm{~h}$, and GMRP1 levels determined. Insulin at 50 and $100 \mathrm{nmol} / 1$ significantly increased GMRP1 production compared with no insulin administration $(p<0.01$; Fig. $5 \mathrm{a}, \mathrm{b})$. After transfection for $72 \mathrm{~h}$ with Gmrpl siRNA or control siRNA, INS-1E cells were exposed to $100 \mathrm{nmol} / \mathrm{l}$ insulin for $10 \mathrm{~min}$ and Akt phosphorylation determined. Insulin-stimulated Akt phosphorylation significantly decreased in cells transfected with Gmrpl siRNA compared with control siRNA-transfected cells $(p<0.01$; Fig. $5 \mathrm{c}, \mathrm{d})$.

GMRP1-mediated Akt-BAD pathway contributed to beta cell proliferation in glucose-infused rats Pancreas sections stained for Ki67 and insulin were used to identify replicating beta cells in saline- or glucose-infused rats. Glucose infusion for 48 and $72 \mathrm{~h}$ significantly increased beta cell replication. Compared with saline infusion, glucose infusion resulted in approximately sevenfold $(p<0.001)$ and tenfold $(p<0.001)$ increases of beta cell replication for 48

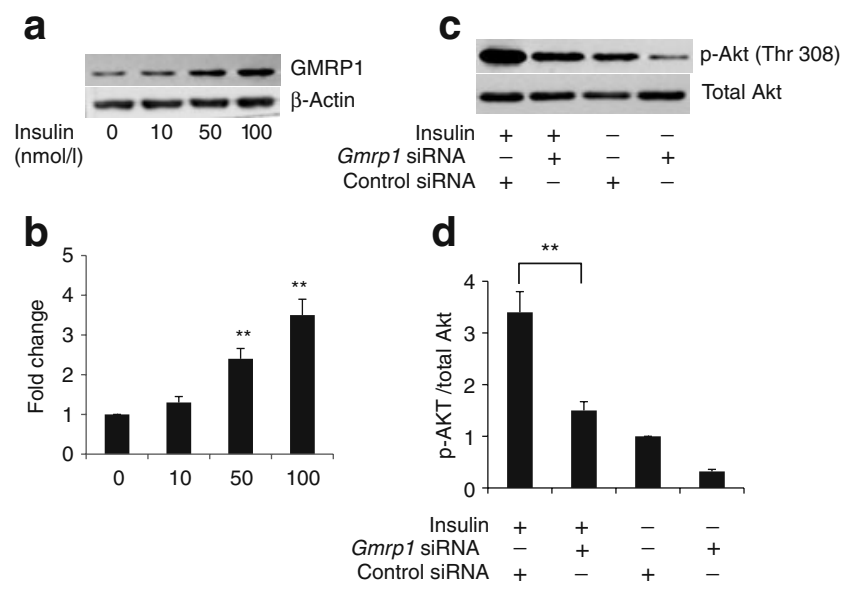

Fig. 5 Involvement of GMRP1 in insulin signalling pathway. a INS$1 \mathrm{E}$ cells were cultured with insulin as indicated for $24 \mathrm{~h}$ and GMRP1 levels determined by western blotting, with (b) quantification of GMRP1. GMRP1 protein levels at $0 \mathrm{nmol} / 1$ insulin were set to 1 ; $* * p<0.01$. c After transfection with Gmrp1 siRNA or control siRNA for $72 \mathrm{~h}$, INS-1E cells were exposed to $100 \mathrm{nmol} / 1$ insulin for $10 \mathrm{~min}$, after which levels of phosphorylated Akt (p-Akt) at Thr 308 and total Akt were determined by western blotting. Akt phosphorylation (p-Akt:total Akt) was quantified (d) using p-Akt at Thr 308 divided by total Akt while Akt phosphorylation in control siRNA-transfected INS-1E cells treated with $0 \mathrm{nmol} / 1$ insulin was set to $1 ; * * p<0.01$ 
and $72 \mathrm{~h}$ respectively (Fig. 6a, b). Beta cell mass also showed 1.3-fold $(p<0.05)$ and 1.6-fold $(p<0.05)$ enhancements in rats infused with glucose for 48 and $72 \mathrm{~h}$ respectively when compared with saline-infused animals (Fig. 6c).

Islets were isolated from glucose- and saline-infused rats, and levels of GMRP1, total Akt, phosphorylated Akt, total BAD and phosphorylated BAD were investigated (Fig. 6d, e). Western blot analysis demonstrated that glucose infusion significantly enhanced GMRP1 production for $24 \mathrm{~h}$ (2.5-fold vs saline infusion, $p<0.01), 48 \mathrm{~h}$ (3.2-fold, $p<0.01)$ and $72 \mathrm{~h}(3.6$-fold, $p<0.01)$. Compared with saline infusion, glucose infusion for 24,48 and $72 \mathrm{~h}$ respectively increased phosphorylation of Akt by 1.7- $(p<0.05)$, 2.6- $(p<0.01)$ and 3.1-fold $(p<0.01)$. Glucose infusion as above also enhanced phosphorylation of BAD by 1.5$(p<0.05), 2.7-(p<0.01)$ and 2.8-fold $(p<0.01)$ respectively.
Immunostaining data demonstrated that GMRP1 production in saline-infused rats was much weaker in beta cells than in non-beta cells. However, glucose infusion markedly increased GMRP1 production in beta cells (Fig. 6f).

GMRP1 might be involved in suppression of beta cell apoptosis in $d b / d b$ mice TUNEL analysis showed that apoptosis occurred in approximately $5.5 \%$ of beta cells in $d b / d b$ mice, but only in around $0.2 \%$ of beta cells in control mice, indicating significant apoptosis of beta cells in $\mathrm{db} / \mathrm{db}$ mice compared with control mice $(p<0.001$; Fig. 7a). Western blot analysis demonstrated that, compared with control mice, GMRP1 production was lowered by $60 \%$ $(p<0.01)$ and phosphorylation of Akt and BAD reduced by $65 \%(p<0.01)$ and $70 \%(p<0.01)$ in islets of $d b / d b$ mice (Fig. 7b, c). Immunohistochemistry data indicated that a

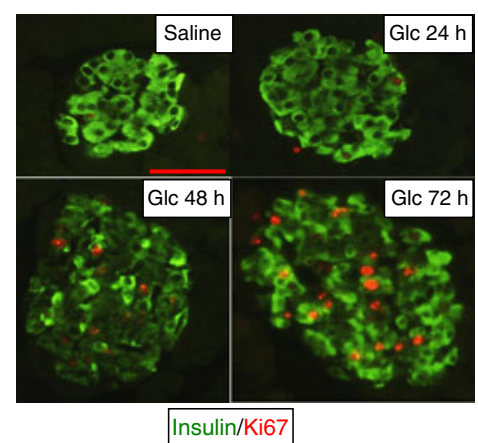

b

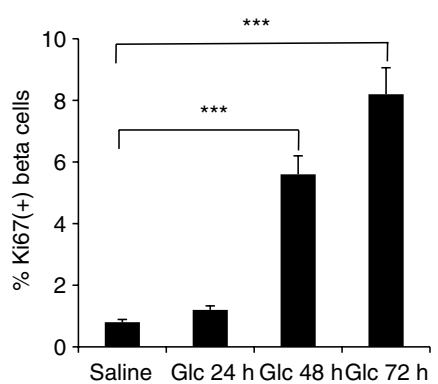

C

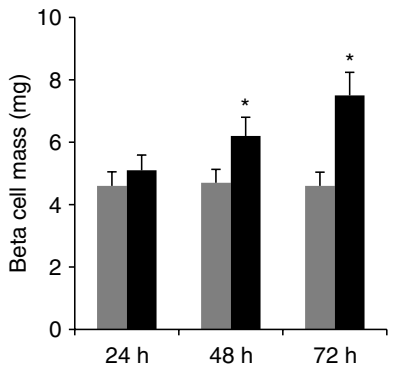

d

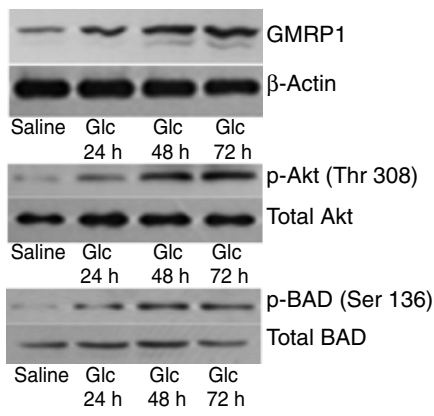

e

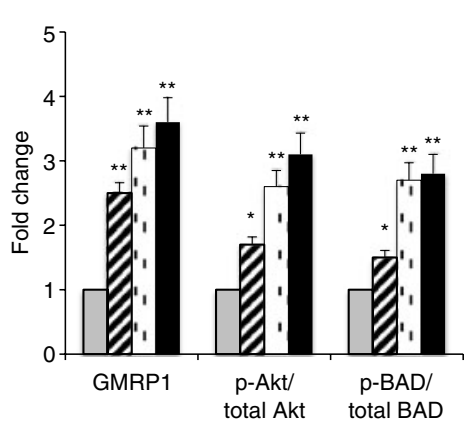

f

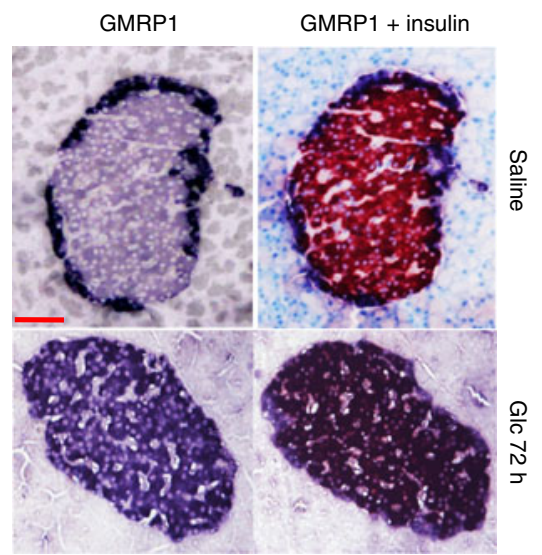

Fig. 6 The roles of GMRP1-mediated Akt-BAD pathway in beta cell proliferation in rats infused as follows: $72 \mathrm{~h}$ with saline, $24 \mathrm{~h}$ with glucose (Glc), $48 \mathrm{~h}$ with glucose (Glc) and $72 \mathrm{~h}$ with glucose (Glc). a Male Sprague-Dawley rats were infused with $50 \%$ (wt/vol) dextrose at a dose of $2 \mathrm{ml} / \mathrm{h}$ for 24,48 and $72 \mathrm{~h}$ respectively. Rats infused with saline for $72 \mathrm{~h}$ were used as controls. Pancreatic sections from these rats were immunostained with anti-insulin (green) and anti-Ki67 (red) antibodies. Scale bar, $50 \mu \mathrm{m}$. b Beta cell proliferation in saline- or glucose-infused rats was assessed as percentage of Ki67-positive beta cells; $* * * p<0.001$. c Beta cell mass of rats infused with saline (grey bars) or glucose (black bars) for indicated times; ${ }^{*} p<0.05$. $\mathbf{d}$ Levels of GMRP1, $\beta$-actin, total Akt, Akt phosphorylated (p-Akt) at Thr 308, total BAD and BAD phosphorylated (p-BAD) at Ser 136 were investigated in islets isolated from saline- or glucose-infused rats. e Statistical analysis of above (d) results. Phosphorylation of Akt (p-Akt:total Akt) or BAD (p-BAD:total BAD) was measured using p-Akt or p-BAD divided by total Akt or BAD. Levels of GMRP1, p-Akt:total Akt and p-BAD:total BAD in glucose-infused rats are shown relative to levels in saline-infused rats set to $1 ;{ }^{*} p<0.05$ and ${ }^{* *} p<0.01$. Grey bars, saline; hatched bars, glucose $24 \mathrm{~h}$; striped bars, glucose $48 \mathrm{~h}$; black bars, glucose $72 \mathrm{~h}$. f Immunostaining for GMRP1 and insulin in pancreatic sections of $72 \mathrm{~h}$ saline- or glucose-infused rats. Scale bar, $100 \mu \mathrm{m}$ 
decreased production in beta cells accounted for total reduction of GMRP1 in islets of $d b / d b$ mice (Fig. 7d).

\section{Discussion}

In this study, we showed that GMRP1 acts as a novel regulator of Akt activity and exerts effects on beta cell proliferation or apoptosis. Mutagenesis studies have revealed that phosphorylation of Thr 308 and Ser 473 is required for Akt activity [23]. 3-Phosphoinositidedependent protein kinase-1 (PDK-1), a well established upstream regulator of Akt, efficiently phosphorylates Akt at Thr 308 in a manner dependent on phosphoinositide-3kinase [35]. In another way, PDK-1 interacts with protein kinase C-related kinase 2 and the PDK-1-protein kinase C-related kinase 2 complex is capable of phosphorylating Akt at Thr 308 and Ser 473 [36]. Integrin-linked kinase has also been suggested to regulate Akt by phosphorylation of Akt at Ser 473 [37]. The calcium/calmodulin-dependent kinase kinase has also been shown to activate Akt by directly phosphorylating it at Thr 308 [38]. Using a yeast two-hybrid screening, GMRP1 was identified as a protein that interacts with Akt3. Further studies have shown that GMRP1 bound to any Akt isoform including Akt1, Akt2 and Akt3 [28]. In vitro experiments on COS7 and NSC34 a

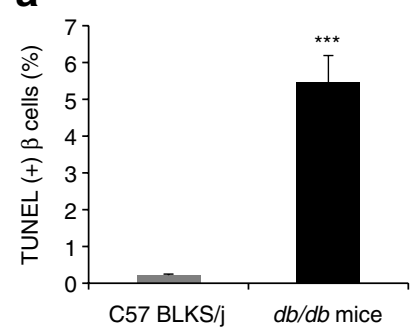

b

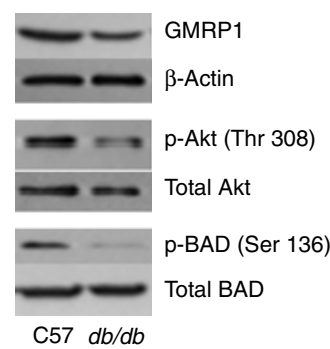

C

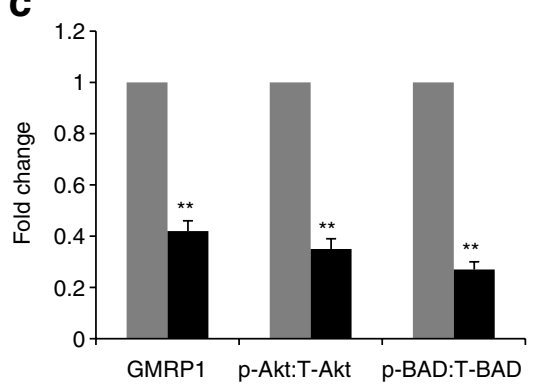

cells indicated that GMRP1 positively regulated Akt phosphorylation at Ser 473 and Thr 308 [28]. In INS-1E cells and rat islets, we have here presented evidence that overproduction of GMRP1 significantly increased phosphorylation of Akt at Thr 308 and at Ser 473, and that knockdown of Gmrpl decreased Akt phosphorylation. Taken together, these findings suggest that GMRP1 serves as a novel upstream regulator of Akt in islet beta cells.

It has been shown that overabundance of GMRP1 promoted NSC34 cell proliferation and suppressed neuronal death caused by mutant superoxide dismutase 1, soluble, and that the proliferative impact of GMRP1 was mediated by enhanced phosphorylation of Akt [28]. In our study, we found that overabundance of GMRP1 significantly increased proliferation of INS-1E cells and rat islets, and that knockdown of Gmrpl led to significantly reduced proliferation and enhancement of apoptosis in beta cells. We showed that expression of GMRPI gene and protein was much greater in insulinoma tissues than in normal islets. It is well known that insulinoma is derived from monoclonal proliferation of beta cells. We also observed that levels of GMRP1 protein in rat insulinoma cells (INS$1 \mathrm{E}$ cells) increased about 3.2-fold in comparison with those in rat islets. These data suggest that GMRP1 is involved in the regulation of beta cell proliferation. In vivo studies have indicated that transgenic mice overexpressing a constitu-

d

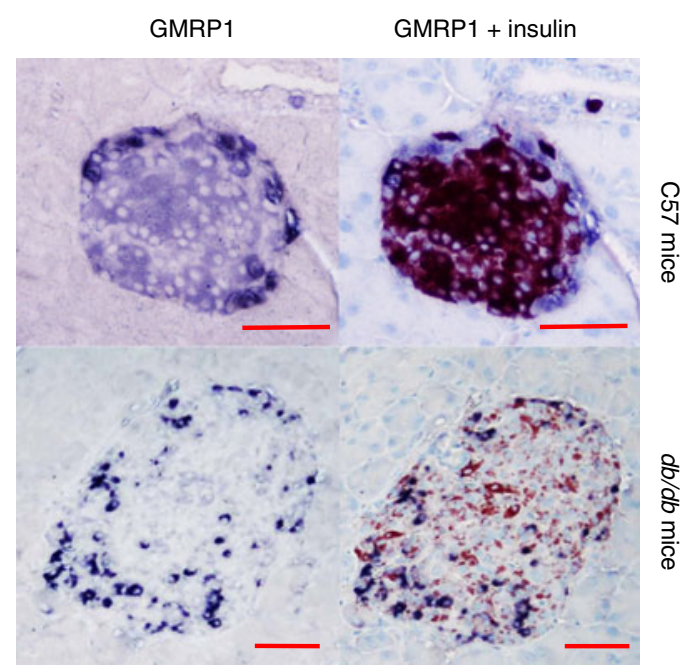

and C57BLKS/J (C57) mice. c Statistical analysis of the above (b) results, where phosphorlyation of Akt (p-Akt:total [T] Akt) or BAD (p-BAD:total [T] BAD) was measured using p-Akt or p-BAD divided by T-Akt or T-BAD. Levels of GMRP1, p-Akt:total Akt and p-BAD: total BAD in $d b / d b$ mice (black bars) are shown relative to those in C57BLKS/J (grey bars) mice set to $1 ; n=4$ per group; ${ }^{* *} p<0.01$. d Immunostaining for GMRP1 and insulin in pancreatic sections of $d b$ / $d b$ and C57BLKS/J mice (d). Scale bar, $100 \mu \mathrm{m}$ 
tively active form of Akt in islet beta cells exhibited striking increases in beta cell mass, proliferation, neogenesis and cell size $[17,18]$. In vitro studies have also shown that enhanced Akt phosphorylation was necessary for and sufficient for glucose-promoted beta cell proliferation [39, 40]. Several targets of Akt have been identified that may contribute to Akt-mediated beta cell survival. It has been established that Akt phosphorylated BAD in vitro and in vivo, and that BAD phosphorylation inhibited cell apoptosis [22, 41]. Evidence also suggests that Aktmediated phosphorylation of BAD inhibited beta cell apoptosis and promoted cell survival [19]. Our data demonstrate that overabundance of GMRP1 increased phosphorylation of Akt and BAD in beta cells, whereas knockdown of Gmrpl, by contrast, decreased phosphorylation of those proteins. However, it has not been ruled out that other downstream targets of Akt participate in the regulation of beta cell survival by GMRP1, e.g. ribosomal protein S6 kinase, p21, cyclin D1, cyclin D2, cyclindependent kinase 4 and glycogen synthase kinase 3 [12, 42-46]. These data imply that the impact of GMRP1 on beta cell survival is accomplished through the Akt-BAD pathway.

Glucose is one of the best stimuli for beta cell replication in vitro and in vivo [1]. We provided evidence that shorttime $(48,72 \mathrm{~h})$ glucose infusion markedly increased beta cell proliferation and mass, a finding that was similar to those of other studies [32, 47-49]. Western blot and immunohistochemistry analysis demonstrated that glucose infusion significantly increased GMRP1 production in beta cells of rat islets. It was also found that Akt and BAD phosphorylation were significantly enhanced by glucose infusion. Furthermore, our in vitro studies on INS-1E cells and isolated islets demonstrated that high glucose culture for short periods $(24,48 \mathrm{~h})$ significantly increased GMRP1 production with enhancement of proliferation and reduction of cell apoptosis. It was also found that knockdown of Gmrp1 significantly lowered cell proliferation induced by high glucose. This suggests that GMRP1 was involved in glucose-regulated survival of beta cells and that the impact of GMRP1 was effected through Akt signalling pathway. To investigate the mechanism by which glucose regulated GMRP1 production, the impact of insulin on GMRP1 production was determined. High insulin significantly increased GMRP1 levels, while knockdown of Gmrp1 inhibited the activation of Akt signalling in response to insulin stimulation. We have shown that high glucose significantly increased insulin secretion in INS-1E cells and rat islets (X. Wang and $\mathrm{R}$. Hu, unpublished data), implying that insulin acts as a mediator in glucose regulation of GMRP1, and also suggesting that GMRP1 is involved in insulin-stimulated activation of Akt signalling pathway. In another way, we attempted to investigate whether GMRP1 was involved in beta cell apoptosis in vivo. TUNEL analysis demonstrated that 5-month-old $d b / d b$ mice had many more apoptotic beta cells than control mice. We also found that GMRP1 production, phosphorylation of Akt and phosphorylation of BAD were all significantly decreased in islets of $d b / d b$ mice. Immunostaining analysis indicated that decreased GMRP1 levels in beta cells contributed to the reduction of GMRP1 production in $d b / d b$ mice islets. Taken together, these data suggest that GMRP1 plays a role in beta cell apoptosis of $d b / d b$ mice.

In summary, this study demonstrated that GMRP1 positively regulated phosphorylation of Akt and participated in regulation of beta cell proliferation or apoptosis. We present evidence that GMRP1 is involved in glucoseregulated cell proliferation and insulin-stimulated Akt signalling pathway in beta cells. We also found that GMRP1 might inhibit beta cell apoptosis. Thus, our data support the notion that the GMRP1-mediated Akt signalling pathway could be a novel component in the regulation of beta cell proliferation and apoptosis.

Acknowledgements This work was supported by grants form National Natural Science Foundation of China to R. Hu (30670999, 30770854 and 81030014), to X. Wang (81070647) and to Z. Zhang (30900502). We would like to thank P. Maechler for kindly providing INS-1E cells. We would also like to thank $\mathrm{H}$. Zhang and $\mathrm{F}$. Li (Shanghai Institute of Endocrinology) for establishment of glucose-infused rat models and assessment of beta cell proliferation and mass.

Duality of interest The authors declare that there is no duality of interest associated with this manuscript.

\section{References}

1. Bonner-Weir S (2000) Islet growth and development in the adult. J Mol Endocrinol 24:297-302

2. Bonner-Weir S, Smith FE (1994) Islet cell growth and the growth factors involved. Trends Endocrinol Metab 5:60-64

3. Finegood DT, Scaglia L, Bonner-Weir S (1995) Dynamics of betacell mass in the growing rat pancreas. Estimation with a simple mathematical model. Diabetes 44:249-256

4. Georgia S, Bhushan A (2004) Beta cell replication is the primary mechanism for maintaining postnatal beta cell mass. J Clin Invest 114:963-968

5. Dor Y, Brown J, Martinez OI et al (2004) Adult pancreatic betacells are formed by self-duplication rather than stem-cell differentiation. Nature 429:41-46

6. Flier SN, Kulkarni RN, Kahn CR (2001) Evidence for a circulating islet cell growth factor in insulin-resistant states. Proc Nat Acad Sci USA 98:7475-7480

7. Alonso LC, Yokoe T, Zhang P et al (2007) Glucose infusion in mice: a new model to induce beta-cell replication. Diabetes 56:1792-1801

8. Miettinen PJ, Ustinov J, Ormio P et al (2006) Downregulation of EGF receptor signaling in pancreatic islets causes diabetes due to impaired postnatal beta-cell growth. Diabetes 55:32993308 
9. Vasavada RC, Garcia-Ocaña A, Zawalich WS et al (2000) Targeted expression of placental lactogen in the beta cells of transgenic mice results in beta cell proliferation, islet mass augmentation, and hypoglycemia. J Biol Chem 275:1539915406

10. Garcia-Ocaña A, Takane KK, Syed MA et al (2000) Hepatocyte growth factor overexpression in the islet of transgenic mice increases beta cell proliferation, enhances islet mass, and induces mild hypoglycemia. J Biol Chem 275:1226-1232

11. Fujinaka Y, Sipula D, Garcia-Ocaña A et al (2004) Characterization of mice doubly transgenic for parathyroid hormonerelated protein and murine placental lactogen: a novel role for placental lactogen in pancreatic beta-cell survival. Diabetes 53:3120-3130

12. Fatrai S, Elghazi L, Balcazar $N$ et al (2006) Akt induces beta-cell proliferation by regulating cyclin D1, cyclin D2, and p21 levels and cyclin-dependent kinase-4 activity. Diabetes 55:318-325

13. Wang Q, Brubaker PL (2002) Glucagon-like peptide-1 treatment delays the onset of diabetes in 8 week-old $\mathrm{db} / \mathrm{db}$ mice. Diabetologia 45:1263-1273

14. Grouwels G, Cai Y, Hoebeke I et al (2010) Ectopic expression of E2F1 stimulates beta-cell proliferation and function. Diabetes 59:1435-1444

15. Huising MO, van der Meulen T, Vaughan JM et al (2010) CRFR1 is expressed on pancreatic beta cells, promotes beta cell proliferation, and potentiates insulin secretion in a glucosedependent manner. Proc Natl Acad Sci USA 107:912-917

16. Fiaschi-Taesch NM, Salim F, Kleinberger J et al (2010) Induction of human beta-cell proliferation and engraftment using a single G1/S regulatory molecule, cdk6. Diabetes 59:1926-1936

17. Tuttle RL, Gill NS, Pugh W et al (2001) Regulation of pancreatic beta-cell growth and survival by the serine/threonine protein kinase Akt1/PKBalpha. Nat Med 7:1133-1137

18. Bernal-Mizrachi E, Wen W, Stahlhut S et al (2001) Islet beta cell expression of constitutively active Akt1/PKB alpha induces striking hypertrophy, hyperplasia, and hyperinsulinemia. J Clin Invest 108:1631-1638

19. Jetton TL, Lausier J, LaRock K et al (2005) Mechanisms of compensatory beta-cell growth in insulin-resistant rats: roles of Akt kinase. Diabetes 54:2294-2304

20. Wang Q, Li L, Xu E et al (2004) Glucagon-like peptide-1 regulates proliferation and apoptosis via activation of protein kinase B in pancreatic INS-1 beta cells. Diabetologia 47:478-487

21. Toker A (2000) Protein kinases as mediators of phosphoinositide 3-kinase signaling. Mol Pharmacol 57:652-658

22. Datta SR, Dudek H, Tao X et al (1997) Akt phosphorylation of BAD couples survival signals to the cell-intrinsic death machinery. Cell 91:231-241

23. Datta SR, Brunet A, Greenberg ME (1999) Cellular survival: a play in three Akts. Genes Dev 13(22):2905-2927

24. Federici M, Hribal M, Perego L et al (2001) High glucose causes apoptosis in cultured human pancreatic islets of Langerhans: a potential role for regulation of specific Bcl family genes toward an apoptotic cell death program. Diabetes 50:1290-1301

25. Hu RM, Han ZG, Song HD et al (2000) Gene expression profiling in the human hypothalamus-pituitary-adrenal axis and full-length cDNA cloning. Proc Natl Acad Sci USA 97:9543-9548

26. Wang XC, Xu SY, Wu XY et al (2004) Gene expression profiling in human insulinoma tissue: genes involved in the insulin secretion pathway and cloning of novel full-length cDNAs. Endocr Relat Cancer 11:295-303

27. Chen J, Xu J, Ying $\mathrm{K}$ et al (2004) Molecular cloning and characterization of a novel human BTB domain-containing gene, BTBD10, which is down-regulated in glioma. Gene 340:61-69
28. Nawa M, Kanekura K, Hashimoto Y et al (2008) A novel Akt/ PKB-interacting protein promotes cell adhesion and inhibits familial amyotrophic lateral sclerosis-linked mutant SOD1induced neuronal death via inhibition of PP2A-mediated dephosphorylation of Akt/PKB. Cell Signal 20:493-505

29. Wang X, Gong W, Liu Y et al (2009) Molecular cloning of a novel secreted peptide, INM02, and regulation of its expression by glucose. J Endocrinol 202:355-364

30. Merglen A, Theander S, Rubi B et al (2004) Glucose sensitivity and metabolism-secretion coupling studied during two-year continuous culture in INS-1E insulinoma cells. Endocrinology 145:667-678

31. El Ouaamari A, Baroukh N, Martens GA, Lebrun P, Pipeleers D, van Obberghen E (2008) miR-375 targets 3'-phosphoinositidedependent protein kinase-1 and regulates glucose-induced biological responses in pancreatic beta-cells. Diabetes 57:2708-2717

32. Kinasiewicz A, Juszczak M, Pachecka J et al (2004) Pancreatic islets isolation using different protocols with in situ flushing and intraductal collagenase injection. Physiol Res 53:327-333

33. Bonner-Weir S, Deery D, Leahy JL et al (1989) Compensatory growth of pancreatic $\beta$-cells in adult rats after short-term glucose infusion. Diabetes 38:49-53

34. Montaña E, Bonner-Weir S, Weir GC (1993) $\beta$-cell mass and growth after syngeneic islet cell transplantation in normal and streptozotocin diabetic C57BL/6 mice. J Clin Invest 91:780-787

35. Alessi DR, Deak M, Casamayor A et al (1997) 3Phosphoinositide-dependent protein kinase-1 (PDK-1): structural and functional homology with the Drosophila DSTPK61 kinase. Curr Biol 7:776-789

36. Balendran A, Casamayor A, Deak M et al (1999) PDK1 acquires PDK2 activity in the presence of a synthetic peptide derived from the carboxyl terminus of PRK2. Curr Biol 9:393-404

37. Delcommenne M, Tan C, Gray V et al (1998) Phosphoinositide-3$\mathrm{OH}$ kinase-dependent regulation of glycogen synthase kinase 3 and protein kinase B/Akt by the integrin-linked kinase. Proc Natl Acad Sci USA 95:11211-11216

38. Yano S, Tokumitsu H, Soderling TR (1998) Calcium promotes cell survival through CaM-K kinase activation of the proteinkinase B pathway. Nature 396:584-587

39. Srinivasan S, Bernal-Mizrachi E, Ohsugi M et al (2002) Glucose promotes pancreatic islet beta-cell survival through a PI 3-kinase/ Akt-signaling pathway. Am J Physiol Endocrinol Metab 283: E784-E793

40. Lingohr MK, Briaud I, Dickson LM et al (2006) Specific regulation of IRS-2 expression by glucose in rat primary pancreatic islet beta-cells. J Biol Chem 281:15884-15892

41. Hengartner MO (2000) The biochemistry of apoptosis. Nature 407:770-776

42. Dickson LM, Lingohr MK, McCuaig J et al (2001) Differential activation of protein kinase $\mathrm{B}$ and $\mathrm{p} 70$ (S6K) by glucose and insulin-like growth factor 1 in pancreatic betacells (INS-1). J Biol Chem 276:21110-21120

43. Pende M, Kozma SC, Jaquet M et al (2000) Hypoinsulinaemia, glucose intolerance and diminished beta-cell size in S6K1deficient mice. Nature 408:994-997

44. Rane SG, Dubus P, Mettus RV et al (1999) Loss of Cdk4 expression causes insulin-deficient diabetes and Cdk4 activation results in beta-islet cell hyperplasia. Nat Genet 22:44-52

45. Marzo N, Mora C, Fabregat ME et al (2004) Pancreatic islets from cyclin-dependent kinase 4/R24C (Cdk4) knockin mice have significantly increased beta cell mass and are physiologically functional, indicating that $\mathrm{Cdk} 4$ is a potential target for pancreatic beta cell mass regeneration in type 1 diabetes. Diabetologia 47:686-694

46. van Weeren PC, de Bruyn KM, de Vries-Smits AM et al (1998) Essential role for protein kinase $\mathrm{B}(\mathrm{PKB})$ in insulin-induced 
glycogen synthase kinase 3 inactivation: characterization of dominant-negative mutant of PKB. J Biol Chem 273:1315013156

47. Bernard C, Thibault C, Berthault MF et al (1998) Pancreatic betacell regeneration after 48 -h glucose infusion in mildly diabetic rats is not correlated with functional improvement. Diabetes $47: 1058-1065$
48. Steil GM, Trivedi N, Jonas JC et al (2001) Adaptation of beta-cell mass to substrate oversupply: enhanced function with normal gene expression. Am J Physiol Endocrinol Metab 280: E788-E796

49. Topp BG, McArthur MD, Finegood DT (2004) Metabolic adaptations to chronic glucose infusion in rats. Diabetologia $47: 1602-1610$ 